DR FILOMENA GIULIA SILEO (Orcid ID : 0000-0001-7380-0576)

DR DANIELE DI MASCIO (Orcid ID : 0000-0002-6560-3393)

PROFESSOR GIUSEPPE RIZZO (Orcid ID : 0000-0002-5525-4353)

Article type : Systematic review

Role of prenatal magnetic resonance imaging in fetuses with isolated agenesis of corpus callosum in the era of fetal neurosonography: a systematic review

\title{
and meta-analysis
}

Filomena Giulia SILEO ${ }^{1,2}$, Daniele DI MASCIO ${ }^{3}$, Giuseppe RIZZO $^{4,5}$, Massimo CAULO ${ }^{6,7}$, Lucia MANGANARO $^{8}$, Emma BERTUCCI $^{2}$, Sophie MASMEJAN ${ }^{9,10}$, Marco LIBERATI ${ }^{11}$, Alice D’AMICO ${ }^{11}$, Luigi NAPPI ${ }^{12}$, Danilo BUCA ${ }^{12}$, Tim VAN MIEGHEM ${ }^{10}$, Asma KHALIL ${ }^{1,13}$, Francesco D’ANTONIO ${ }^{11}$

1: Fetal Medicine Unit, Saint George's Hospital, London, UK

2: Prenatal Medicine Unit, Obstetrics and Gynecology Unit, Department of Medical and Surgical Sciences for Mother, Child and Adult, University of Modena and Reggio Emilia, Modena, Italy 3: Department of Maternal and Child Health and Urological Sciences, Sapienza University of Rome, Italy

4: Division of Maternal and Fetal Medicine, Ospedale Cristo Re, University of Rome Tor Vergata, Rome, Italy

5: Department of Obstetrics and Gynecology, The First I.M. Sechenov Moscow State Medical University, Moscow, Russia

6: ITAB Institute of Advanced Biomedical Technologies, University "G. d'Annunzio", Chieti, Italy.

This article has been accepted for publication and undergone full peer review but has not been through the copyediting, typesetting, pagination and proofreading process, which may lead to differences between this version and the Version of Record. Please cite this article as doi: 10.1111/AOGS.13958

This article is protected by copyright. All rights reserved 
7: SS Annunziata Hospital, Department of Neuroscience, Imaging and Clinical Sciences,

University "G. d'Annunzio", Chieti, Italy.

8: Department of Radiology, Sapienza University of Rome, Rome, Italy

9: Obstetrics Unit, Department of Mother and Child, Centre Hospitalier Universitaire Vaudois, Lausanne, Switzerland

10: Fetal Medicine Unit, Department of Obstetrics and Gynecology, Mount Sinai Hospital and University of Toronto, Toronto, Canada

11: Center for Fetal Care and High-risk Pregnancy, Department of Obstetrics and Gynecology, University Hospital of Chieti, Chieti, Italy

12: Department of Obstetrics and Gynecology, University of Foggia, Foggia, Italy

13: Vascular Biology Research Centre, Molecular and Clinical Sciences Research Institute, St George's Hospital, University of London, London, UK

\section{Corresponding Author:}

Francesco D’Antonio

Center for Fetal care and High Risk Pregnancy, Department of Obstetrics and Gynecology, University Chieti, Chieti, Italy

Email: francesco.dantonio@unich.it

\section{Conflicts of interest}

None to declare. 


\section{ABSTRACT}

Introduction: Corpus callosum agenesis (ACC) is frequently diagnosed during fetal life; its prognosis depends also on additional anomalies. The additional value of fetal magnetic resonance imaging (MRI) in fetuses with 'isolated' complete (cACC) and partial (pACC) agenesis of the corpus callosum on ultrasound is still debated. Material and Methods: We performed a systematic literature review and meta-analysis including fetuses with a prenatal diagnosis of cACC and pACC without associated structural anomalies on ultrasound, undergoing fetal MRI. The primary outcome was the rate of additional anomalies detected at fetal MRI. Further analyses assessed the effect of type of ultrasound assessment (neurosonography vs standard axial assessment), gestational age at fetal MRI, rate of postnatally detected brain anomalies. Randomeffect meta-analyses of proportions were used to analyze the data. Results: Fourteen studies (798 fetuses) were included. In cases with isolated cACC, 10.9\%(95\% CI 4.1-20.6) and 4.3\% (95\% CI 1.4-8.8) additional anomalies were detected by fetal MRI and postnatally respectively. Stratifying according to the type of ultrasound assessment, the rate of associated anomalies detected only on fetal MRI was 5.7\% (95\% CI 0.5-16.0) with dedicated neurosonography and $18.5 \%$ (95\% CI 7.832.4) with a standard axial assessment. In fetuses with isolated pACC, 13.4\% (95\% CI 4.0-27-0) and $16.2 \%$ (95\% CI 5.9-30-3) additional anomalies were detected by fetal MRI or postnatally respectively. Stratifying according to the type of ultrasound assessment, the rate of associated anomalies detected only on fetal MRI was $11.4 \%$ (95\% CI 2.7-25-0) when dedicated neurosonography was performed. Cortical and posterior fossa anomalies represented the most common anomalies missed at ultrasound with both $\mathrm{cACC}$ and pACC. Due the very small number of included cases, stratification according to early ( $<24$ weeks of gestation) and late ( $>24$ weeks) fetal MRI couldn't be done either for cACC or pACC. Conclusions: The rate of associated anomalies detected exclusively at fetal MRI in isolated ACC undergoing neurosonography is lower compared to what previously reported. Cortical and posterior fossa anomalies are among the most common anomalies detected exclusively at MRI, thus confirming the crucial role of fetal MRI in determining the prognosis of these fetuses. However, some anomalies still go undetected prenatally, and this should be stressed during parental counselling.

\section{Keywords}


agenesis of corpus callosum, magnetic resonance imaging, neurosonography, ultrasound, corpus callosum

\section{Abbreviations:}

CI: confidence interval;

cACC: complete agenesis of corpus callosum

pACC: partial agenesis of corpus callosum;

ACC: agenesis of corpus callosum;

CNS: central nervous system

ISUOG International Society of Ultrasound in Obstetrics \& Gynecology

NOS Newcastle-Ottawa Scale

OR odds ratio

\section{Key Message:}

The rate of associated anomalies detected exclusively at MRI is lower than previously reported in fetuses with corpus callosum agenesis undergoing neurosonography. MRI is crucial in detecting more cortical and posterior fossa anomalies; however, some anomalies still go undetected prenatally. 


\section{INTRODUCTION}

The corpus callosum is the largest commissure in the central nervous system (CNS) with a cardinal role in the execution of physical, cognitive and affective functions. ${ }^{1-4}$ Developmental defects of the corpus callosum, including either complete (cACC) or partial (pACC) agenesis, hypoplasia or dysplasia are among the most common CNS anomalies diagnosed during fetal life. Postnatally, the prevalence of callosal defects ranges from 1.8 per 10000 in the general population to $230-600$ per 10000 in children with neurodevelopmental disabilities. ${ }^{2-3,5}$

Agenesis of corpus callosum (ACC) is a heterogeneous condition that can either be caused by chromosomal, infectious, vascular or toxic disorders. ${ }^{3}$ Chromosomal anomalies can be found in $5 \%$ of children with isolated $\mathrm{ACC},{ }^{2}$ but in up to $18 \%$ of fetuses when $\mathrm{ACC}$ is associated with other CNS and extra-CNS anomalies, and are the main determinant of postnatal outcome in children affected by these anomalies. ${ }^{4-6}$

Prenatal screening for $\mathrm{cACC}$ is mainly based upon indirect signs including absence of the cavum septi pellucidi (CSP), abnormalities of the lateral ventricles and widening of the interhemispheric fissure, while its confirmation requires the lack of visualization of the $\mathrm{CC}$ in a sagittal view of the fetal brain. Prenatal diagnosis of pACC is much more challenging and many of the indirect signs found in fetuses with cACC may be missing.

In the last few years, fetal magnetic resonance imaging (MRI) has been claimed to play an important role in detecting additional fetal brain anomalies, and some studies suggest with a significantly higher accuracy than ultrasound. ${ }^{7} \mathrm{~A}$ recent sub-analysis of the MERIDIAN study, a large prospective study assessing the role of fetal MRI in detecting associated anomalies in fetuses with CNS malformations, reported that the diagnostic accuracy for detecting ACC as a distinct entity was only $40.0 \%$ for ultrasound and $92.7 \%$ for MRI. ${ }^{8}$

However, this study did not describe the imaging protocol adopted for ultrasound examination. We have recently reported that, in fetuses with isolated ventriculomegaly, the rate of additional anomalies found exclusively at fetal MRI was significantly lower than previously reported when a state-of-the-art multiplanar assessment of the fetal brain (neurosonogram) was performed. ${ }^{9-11}$

The primary aim of this systematic review was to report on the role of fetal MRI in detecting additional anomalies in fetuses with isolated ACC on ultrasound; the secondary aim was 
to elucidate the rate of additional anomalies detected at MRI according to gestational age at scan and type of ultrasound assessment performed (standard vs dedicated neurosonography).

This article is protected by copyright. All rights reserved 


\section{MATERIAL AND METHODS}

\section{Protocol, eligibility criteria, information sources and search}

This review was performed according to an a priori designed protocol recommended for systematic reviews and meta-analysis. ${ }^{12-14}$ Medline, Embase and Cochrane databases were searched electronically in June 2018 and the search was updated in April 2020, utilizing combinations of the relevant medical subject heading (MeSH) terms, key words, and word variants for "magnetic resonance imaging" and "corpus callosum" (Supporting Information Table $\mathrm{S} 1$ and S2). Reference lists of relevant articles and reviews were hand searched for additional reports. Prisma and MOOSE guidelines were followed. ${ }^{15-17}$ The study was registered with the PROSPERO database (Registration number: CRD42018107284).

\section{Inclusion criteria, outcomes' measures and study selection}

Only studies reporting on fetuses with a prenatal confirmed diagnosis of corpus callosum anomalies on ultrasound with no associated structural anomalies, undergoing prenatal MRI were included. To be included, a neurosonography (according to International Society of Ultrasound in Obstetrics \& Gynecology (ISUOG) guidelines) or a brain assessment by a fetal medicine specialist (therefore likely to be multiplanar) had to performed. The primary outcome was the rate of additional anomalies detected on prenatal MRI. For the purpose of the analysis, we divided the population of fetuses affected by corpus callosum anomalies into two groups:

1. Complete agenesis of the corpus callosum

2. Partial agenesis of the corpus callosum, as defined by authors of the primary study.

We decided to consider complete and partial agenesis separately because they represents two different conditions potentially reflecting different etiologies, since partial agenesis may be due not only to arrest in development but also to disruptive events according to which part is missing.

The secondary outcome was the rate of additional anomalies detected according to the type of ultrasound assessment (multiplanar neurosonography vs basic brain assessment), gestational age at MRI ( $\leq 24$ compared to $>24$ weeks of gestation) and the rate of anomalies detected exclusively at the time of postnatal brain imaging (either ultrasound or MRI). Anomalies were categorized as:

- Posterior fossa anomalies, including all defects involving the cerebellar vermis and/or hemispheres, as well as the cisterna magna 
- Intra-ventricular hemorrhage

- Cortical anomalies, including all abnormalities associated with a primary defect in neuronal migration towards the cortical surface of the brain

- Periventricular heterotopia

- Other white matter anomalies

- Arachnoid cyst

- Periventricular cysts

- Intracranial lipomas

- Complex brain anomalies including all defects characterized by the presence of multiple intra-cranial anomalies

- Other cerebral anomalies

Only studies reporting the prevalence of brain anomalies diagnosed on prenatal MRI in fetuses affected by isolated ACC were considered eligible for the inclusion in the present systematic review. For the ascertainment of the primary and secondary outcomes, we did not consider as associated anomalies dimensional increase in the brain structures, such as ventriculomegaly or mega cisterna magna or findings typically associated with ACC such as colpocephaly, widening of the interhemispheric space, an abnormal course of the pericallosal artery or an abnormal sulcation pattern.

Studies including cases with fetal anomalies were excluded in view of the higher risk of associated brain anomalies in cases presenting with additional anomalies. Likewise, studies not specifying whether fetuses were segregated by complete or partial agenesis of the corpus callosum were not considered eligible for the inclusion. Case reports, conference abstracts and case series with fewer than 3 cases were excluded to avoid publication bias. Furthermore, studies published before 2000 were not included as advances in prenatal imaging make them less relevant.

Two authors (FGS, DDM) reviewed all abstracts independently. Agreement regarding potential relevance was reached by consensus; full text copies of those papers were obtained, and the same two reviewers independently extracted relevant data regarding study characteristics and pregnancy outcome. Inconsistencies were discussed by the reviewers and consensus reached or by discussion with a third author (FDA). If more than one study was published on the same cohort with identical endpoints, only the report containing the most comprehensive information on the 
population was included to avoid overlapping populations. We contacted the authors of those studies where information needed for the review was not presented in the article, but likely to have been recorded initially.

Quality assessment of the included studies was performed using the Newcastle-Ottawa Scale (NOS) for cohort studies. According to NOS, each study is judged on three characteristics: the selection of the study groups, the comparability of the groups, and the ascertainment of the outcome of interest. ${ }^{18}$ According to NOS a study can be awarded a maximum of one star for each numbered item within the Selection and Outcome categories. A maximum of two stars can be given for Comparability. ${ }^{18}$

\section{Statistical analyses}

First, we performed random-effect meta-analyses of proportions to estimate the pooled rates of each brain anomaly in fetuses affected by isolated $\mathrm{ACC}$ on ultrasound undergoing MRI assessment. For the purpose of the analysis, we compute this outcome in the overall population of fetuses with ACC and in those undergoing dedicated neurosonography and standard assessment of fetal brain. Second, we aimed to use random-effect head-to-head meta-analyses to directly compare the risk of detecting an associated anomaly in fetuses undergoing early ( $\leq 24$ weeks) compared to late ( $>24$ weeks) fetal MRI, expressing the results as summary odds ratio (OR) and relative $95 \%$ confidence interval (CI), and evaluating the statistical heterogeneity through $\mathrm{I}^{2}$ metric. ${ }^{19}$ Finally, a sub-group analysis including only fetuses with isolated ACC and no associated chromosomal or genetic anomalies was also performed.

Publication bias was assessed graphically through funnel plots and formally through Egger's regression asymmetry test ${ }^{20}$; formal tests for funnel plot asymmetry were not performed when the total number of publications included for each outcome was $<10$ because the power of the test is too low to distinguish chance from real asymmetry. ${ }^{21}$ RevMan 5.3 (The Cochrane Collaboration, 2014) and Stata, version 13.1 (Stata Corp., College Station, TX, USA) were used to analyze the data.

\section{RESULTS}

This article is protected by copyright. All rights reserved 


\section{General characteristics}

Five hundred and forty articles were identified, 109 were assessed with respect to their eligibility for inclusion and 14 studies were included in the systematic review (Table 1, Figure 1, Supporting Information Table S1) ${ }^{22-35}$. These 14 studies included 798 fetuses, of which 258 were affected by isolated ACC, defined as either complete or partial absence of the CC with no additional anomalies on ultrasound. The definition of isolated ACC was based upon multiplanar neurosonography in seven studies (460 fetuses), while a standard sonographic assessment of fetal brain was undertaken in the remaining seven studies (338 fetuses). The majority of MRI examinations were performed after 24 weeks of gestation, both for those fetuses undergoing neurosonography and those having standard assessment of the fetal brain.

The results of the quality assessment of the included studies are presented in Table 2. Most of the included studies showed a good overall score. The main weaknesses of the studies were their retrospective design, small sample size, and different gestational ages at examination; furthermore, we could not perform any meaningful sub-analysis according to the gestational age at scan due to the paucity of these data.

\section{Complete ACC}

Twelve studies ${ }^{22-32,34-35}$ (178 fetuses) explored the role of fetal MRI in detecting associated anomalies in fetuses with a prenatal diagnosis of isolated complete ACC on ultrasound. Overall, MRI detected 10.9\% (95\% CI 4.1-20.6) of fetal anomalies not detected on ultrasound, while the rate of additional anomalies detected only at birth and missed also at prenatal MRI was 4.3\% (95\% CI 1.4-8.8) (Table 3). However, when stratifying the analysis according to the type of ultrasound assessment, the rate of associated anomalies detected only on MRI was 5.7\% (95\% CI 0.5-16.0) when dedicated neurosonography was performed and 18.5\% (95\% CI 7.8-32.4) in cases undergoing a standard assessment of fetal brain (Table 3 ). The rate of additional anomalies detected exclusively at MRI was even lower when considering fetuses with isolated ACC and no associated genetic or chromosomal anomalies, with no additional defects found at MRI in this subgroup of fetuses (PP: 0\%, $955 \mathrm{CI} 0-17.0 ; \mathrm{I}^{2}: 0 \%$ ), although this analysis was affected by the very small number of included cases.

When stratifying the analysis according to the type of anomaly, the majority of additional findings missed at ultrasound and detected only at MRI were cortical anomalies in $6.3 \%(95 \% \mathrm{CI}$ $3.0-10.6)$, followed by periventricular heterotopia in 3.5\% (95\% CI 1.3-6-6), complex anomalies 
in $3.3 \%$ (95\% CI $0.8-7.3)$ and posterior fossa anomalies in $2.8 \%(95 \%$ CI $0.9-5.7)$ of cases. There were no cases of hemorrhage or destructive brain anomalies (Table 4).

Finally, additional anomalies also missed at fetal MRI and only detected on postnatal imaging were cortical anomalies in 3.1\% (95\% CI 0.7-7.1) and hemorrhage in $2.9 \%$ (95\% CI 0.6 6.8) of cases (Table 4).

Unfortunately, due the very small number of included cases we could not perform a comprehensive analysis between early ( $<24$ weeks of gestation) and late ( $>24$ weeks) MRI.

\section{Partial ACC}

Ten studies ${ }^{22-24,27-31,33-34}$ (35 fetuses) explored the role of fetal MRI in detecting associated anomalies in fetuses with a prenatal diagnosis of isolated partial ACC on ultrasound. Overall, MRI detected 13.4\% (95\% CI 4.0-27-0) of fetal anomalies not detected on ultrasound, while the rate of additional anomalies detected only postnatally and missed at prenatal MRI was $16.2 \%$ (95\% CI 5.9-30-3) (Table 5). However, when stratifying the analysis according to the type of ultrasound assessment, the rate of associated anomalies detected only on MRI was $11.4 \%$ (95\% CI 2.7-25-0) when dedicated neurosonography was performed and 16.9\% (95\% CI 1.3-44-8) in cases undergoing a basic assessment of fetal brain (Table 5). The rate of additional anomalies detected exclusively at MRI was even lower when considering fetuses with isolated ACC and no associated genetic or chromosomal anomalies, with no additional defects found at MRI in this sub-group of fetuses (PP: 0\%, 955 CI 0-33.7; I²: 0\%), although this analysis was affected by the very small number of included cases.

When stratifying the analysis according to the type of anomaly, the majority of additional findings missed at ultrasound and detected only at MRI were cortical anomalies in $9.3 \%$ (95\% CI 2.4-20.1) of cases, followed by posterior fossa anomalies in 7.6\% (95\% CI 1.6-17.7) of cases and complex anomalies in 7\% (95\% CI 1.2-16.8) of cases. There were no cases of periventricular heterotopia, hemorrhage or destructive brain anomalies (Table 6).

Finally, additional anomalies missed at prenatal MRI and detected only postnatally were periventricular heterotopia in 10.9\% (95\% CI 1.9-25.8), cortical anomalies in $8.9 \%$ (95\% CI 1.8 20.6) and destructive brain anomalies in 7.9\% (95\% CI 1.3-19-2) of cases (Table 6). Unfortunately, due the very small number of included cases we could not perform a comprehensive analysis between early ( $<24$ weeks of gestation) and late ( $>24$ weeks) MRI. 


\section{DISCUSSION}

The findings from this systematic review show that, in fetuses affected by isolated ACC, the rate of associated anomalies detected exclusively at MRI was about $11 \%$. This is lower than what was previously reported. ${ }^{8}$ The added benefit of MRI was even lower when a dedicated neurosonogram was performed, with only $\sim 5 \%$ of fetuses showing additional anomalies at MRI. The most common anomalies missed at ultrasound and diagnosed only at fetal MRI were cortical and posterior fossa anomalies as well as periventricular heterotopia. This highlights the utility of MRI assessment in view of the fact that such undetected anomalies at ultrasound can significantly impact the postnatal outcome of these children. Cortical anomalies and heterotopia were also among the most common abnormalities missed at fetal MRI and detected only after birth.

As we here performed a meta-analysis of multiple studies, we were able to gather information on an important number of fetuses with isolated ACC. The validity of our study is nevertheless limited by the quality of the original studies, which all had a retrospective design, a small sample size and were heterogeneous in gestational age at ultrasound and MRI assessment. The interval between ultrasound and MRI was not specified ${ }^{23-25,27-31,34}$ or varied markedly across studies, ranging between 14 days $^{26,32,34-35}$ to more than 4 weeks ${ }^{22}$ and therefore the role of MRI might have been overestimated due to the evolutive nature of some abnormalities (such as heterotopias) rather than the imaging method used for detecting them.

Another possible limitation was the incomplete reporting of characteristics that could potentially influence diagnostic performance of ultrasound. Only seven studies clearly stated that ultrasound assessment included neurosonography ${ }^{22-25,27,30,33}$ while in the remaining no information on ultrasound imaging protocol could be extracted ${ }^{26,28-29,31-32,34-35}$. Nonetheless we assumed that, since a classification of the anomaly in complete or partial ACC was available, the assessment included at least a mid-sagittal view of the brain.

Another possible limitation of the study is that we accepted authors' definition of partial agenesis of corpus callosum; although we are aware that there might be a wide discrepancy among studies, we made this choice because of the small number of fetuses with pACC.

Furthermore, not all cases presenting additional anomalies on MRI were screened for aneuploidies or infection, so that it might be entirely possible that some cases affected by aneuploidies or infections diagnosed only after birth were included in the analysis. 
To our knowledge, three systematic reviews have tried to address the additional value of fetal MRI when a CNS abnormality is suspected on ultrasound, but none of them specifically focused on ACC anomalies. ${ }^{7,36-37}$

In a systematic review of 27 studies including 1184 fetuses with suspected brain abnormalities on neurosonography, additional anomalies were found at fetal MRI in 19\% of cases. ${ }^{36} \mathrm{~A}$ high disagreement between ultrasound and MRI was also reported in another systematic review of 13 studies including 710 fetuses with a CNS anomaly, in which MRI detected additional anomalies in $22 \%$ of cases. ${ }^{7}$ Finally, a recent systematic review including 959 fetuses from 34 studies reported that disagreement between ultrasound and MRI was $24 \%$ when assessing midline anomalies, mainly due to missed or wrong interpretations at ultrasound. However, the authors did not perform a subgroup analysis on ACC alone, and therefore midline anomalies involved also included holoprosencephaly and absent cavum septum pellucidi. ${ }^{37}$ More importantly, these reviews did not take into account whether the type of ultrasound assessment (standard vs neurosonography) affected the rate of additional anomalies found exclusively at MRI.

Isolated ACC, either complete or partial, represents an important clinical challenge for maternal fetal specialists affecting both counseling and diagnostic work-up. The presence of associated anomalies is one of the main determinants of postnatal outcomes in children affected by these anomalies. Impaired neurocognitive outcome has been shown to affect about $45 \%$ of children with associated anomalies, although several degrees of disorders of motor control, coordination, language, and cognitive status have been described also in children with of isolated ACC. ${ }^{2-3}$ The potential impact of associated anomalies in determining the outcome of children with ACC highlights the need for a thorough ultrasound assessment of fetuses with ACC but also questions on how prenatal imaging is able to diagnose truly isolated cases of ACC at midgestation.

Some anomalies may appear only later in gestation, and this may have a huge impact on short- and long-term prognosis, which should be mentioned during prenatal counseling. In 2017, a large prospective, multicenter study involving 16 centers across the United Kingdom (the MERIDIAN Study) showed that additional anomalies detected exclusively at MRI were found in nearly $14 \%$ of fetuses with failed commensuration diagnosed at ultrasound, and these results had a significant impact on clinical management in over $44 \%$ of cases. ${ }^{8}$

The results from this study support our previous findings on the diagnostic accuracy of neurosonography in isolated mild and moderate ventriculomegaly, ${ }^{9-10}$ and furtherly highlight the 
need of a detailed multiplanar assessment of fetal brain, as suggested by ISUOG 2007 guidelines, in case of suspected CNS structural defect. ${ }^{11,38}$ Despite this, undetected anomalies at ultrasound remain and these include posterior fossa and cortical malformations, which are associated with poor short- and long-term neurodevelopmental outcome. This highlights the crucial role of prenatal MRI in determining the prognosis of fetuses affected by apparently isolated ACC. This is particular important for those couples that want to have the most comprehensive prenatal information in order to make the most conscious choice about the future of their pregnancy.

For couple not considering termination as an option for their pregnancy, we do not advocate the need of a fetal MRI since this is unlikely to make a difference for the couple and imaging can be postponed after birth. The role of fetal MRI is however challenging also for patients uncertain about the future of their pregnancy: while additional abnormalities detected only on MRI implies an increased likelihood of neurological impairment after birth ${ }^{4}$, the absence of them cannot be of total reassurance since $4 \%$ of fetuses with isolated cACC and $16 \%$ of those with pACC showed additional anomalies at postnatal imaging.

Timing of fetal MRI represent another peculiar issue. Currently, there is no convincing evidence whether to perform MRI in early second trimester (22-24 weeks) or later in gestation (28-30 weeks), but it is common clinical practice to delay fetal MRI in pregnancies with suspected fetal brain anomalies, as some malformations can become evident only later on during pregnancy. In the present systematic review, it was not possible to stratify the data according to gestational age at MRI; however, in a recent large multicenter, MRI performed at or after 24 weeks was an independent factor for the detection of additional anomalies missed at ultrasound in fetuses with ventriculomegaly detected exclusively. This is not surprising, as the most common anomalies detected only at MRI in this study were hemorrhage and migration disorders, that frequently occur after the second trimester of pregnancy. ${ }^{39}$

Estimation of how prenatal imaging is able to confidently confirm isolated ACC at midgestational is fundamental as it would allow parents to undertake a more conscious decision on their pregnancy, especially in countries in which termination of pregnancy is not allowed after 24 weeks of gestation. Unfortunately, the very small number of cases available for the analysis did not allow a comprehensive estimation on how early MRI can confidently confirm isolated ACC before 24 weeks of gestation. In this scenario, prenatal counselling should stress the fact that a proportion of fetuses with a prenatal diagnosis of isolated ACC confirmed at MRI in the second trimester of pregnancy can show additional anomalies later on in gestation or at postnatal imaging. 


\section{CONCLUSION}

The rate of associated anomalies detected exclusively at MRI in fetuses with isolated ACC undergoing neurosonography is lower compared to what has been previously reported in studies not reporting a clear imaging protocol. Cortical and posterior fossa anomalies are among the most common anomalies detected exclusively at MRI, thus confirming the crucial role of prenatal MRI in determining the prognosis of fetuses affected by these anomalies. Despite fetal MRI, some anomalies can still only be detected postnatally and this should be stressed during parental counselling.

\section{Acknowledgements:}

We thank Dr. Fratelli, Dr Bhide, Dr Turkyilmaz, Dr Masmejan, Dr Ghi, Dr Ruland, Dr Kasprian and Dr Maiz for providing further information from their studies.

\section{REFERENCES}

1. Lerman-Sagie T, Ben-Sira L, Achiron R et al. Thick fetal corpus callosum: an ominous sign? Ultrasound Obstet Gynecol. 2009;34:55-61

2. D'Antonio F, Pagani G, Familiari A, et al. Outcomes Associated With Isolated Agenesis of the Corpus Callosum: A Meta-analysis. Pediatrics. 2016; 138:e20160445.

3. Leombroni M, Khalil A, Liberati M, D'Antonio F. Fetal midline anomalies: Diagnosis and counselling Part 1: Corpus callosum anomalies. Eur J Paediatr Neurol. 2018;22:951-962.

4. Santo S, D'Antonio F, Homfray T, et al. Counseling in fetal medicine: agenesis of the corpus callosum. Ultrasound Obstet Gynecol. 2012;40:513-521.

5. Sotiriadis A, Makrydimas G. Neurodevelopment after prenatal diagnosis of isolated agenesis of the corpus callosum: an integrative review. Am J Obstet Gynecol. 2012; 206:337.e1-337.e3375.

6. Tang PH, Bartha AI, Norton ME, Barkovich AJ, Sherr EH, Glenn OA. Agenesis of the corpus callosum: an MR imaging analysis of associated abnormalities in the fetus. AJNR Am J Neuroradiol. 2009; 30:257-263. 
7. Rossi AC, Prefumo F. Additional value of fetal magnetic resonance imaging in the prenatal diagnosis of central nervous system anomalies: a systematic review of the literature. Ultrasound Obstet Gynecol 2014; 44:388-393.

8. Griffiths PD, Brackley K, Bradburn M, et al. Anatomical subgroup analysis of the MERIDIAN cohort: failed commissuration. Ultrasound Obstet Gynecol. 2017; 50:753760.

9. Di Mascio D, Sileo FG, Khalil A, et al. Systematic review and meta-analysis on the role of prenatal magnetic resonance imaging in the era of fetal neurosonography: mild and moderate ventriculomegaly. Ultrasound Obstet Gynecol 2019;54:164-171.

10. ENSO working group. Role of prenatal magnetic resonance imaging in fetuses with isolated mild or moderate ventriculomegaly in the era of neurosonography: a multicenter study. Ultrasound Obstet Gynecol. 2020 Jan 9. doi: 10.1002/uog.21974. Online ahead of print.

11. ISUOG Guidelines. Sonographic examination of the fetal central nervous system: guidelines for performing the 'basic examination' and the 'fetal neurosonogram' Ultrasound Obstet Gynecol 2007; 29:109-116.

12. Henderson LK, Craig JC, Willis NS, Tovey D, Webster AC. How to write a Cochrane systematic review. Nephrology (Carlton) 2010; 15: 617-624.

13. NHS Centre for Reviews and Dissemination. Systematic reviews: CRD ${ }^{\text {ee }}$ guidance for undertaking reviews in health care. University of York: York (UK), 2009. Available at: https://www.york.ac.uk/media/crd/Systematic_Reviews.pdf.

14. Welch V, Petticrew M, Petkovic J, et al. Extending the PRISMA statement to equityfocused systematic reviews (PRISMA-E 2012): explanation and elaboration. J Clin Epidemiol 2016; 70:68-89.

15. Moher D, Liberati A, Tetzlaff J, Altman DG, and the PRISMA Group. Preferred Reporting Items for Systematic Reviews and Meta-Analyses: The PRISMA Statement. Ann Intern Med 2009; 151:264-269.

16. Zorzela L, Loke YK, Ioannidis JP, et al; PRISMA harms group. PRISMA harms checklist: improving harms reporting in systematic reviews. BMJ 2016; 352:i157.

17. Stroup DF, Berlin JA, Morton SC, et al. Meta-analysis of observational studies in epidemiology: a proposal for reporting. Meta-analysis of Observational Studies in 
Epidemiology (MOOSE) group. JAMA 2000; 283:2008-2012.

18. Newcastle-Ottawa Scale for assessing the quality of nonrandomised studies in metaanalyses. Available at: http://www.ohri.ca/programs/clinical_epidemiology/oxford.asp

19. Higgins J, Thompson S, Deeks J, Altman D. Statistical heterogeneity in systematic reviews of clinical trials: a critical appraisal of guidelines and practice. J Health Serv Res Policy. 2002;7:51-61.

20. Egger M, Davey Smith G, Schneider M, Minder C. Bias in meta-analysis detected by a simple, graphical test. BMJ. 1997; 315: 629-634.

21. Hunter JP, Saratzis A, Sutton AJ, Boucher RH, Sayers RD, Bown MJ. In meta-analyses of proportion studies, funnel plots were found to be an inaccurate method of assessing publication bias. J Clin Epidemiol. 2014; 67: 897-903

22. Turkyilmaz G, Sarac Sivrikoz T, Erturk E, et al. Utilization of neurosonography for evaluation of the corpus callosum malformations in the era of fetal magnetic resonance imaging. J Obstet Gynaecol Res. 2019;45:1472-1478.

23. Santirocco M, Rodó C, Illescas T, et al. Accuracy of prenatal ultrasound in the diagnosis of corpus callosum anomalies. J Matern Fetal Neonatal Med. 2019 Apr 29;1-6. doi: 10.1080/14767058.2019.1609931. Online ahead of print.

24. Masmejan S, Blaser S, Keunen J, et al. Natural History of Ventriculomegaly in Fetal Agenesis of the Corpus Callosum. J Ultrasound Med. 2020;39:483-488.

25. de Wit MC, Boekhorst F, Mancini GM, et al. Advanced genomic testing may aid in counseling of isolated agenesis of the corpus callosum on prenatal ultrasound. Prenat Diagn. 2017;37:1191-1197.

26. Griffiths PD, Brackley K, Bradburn M, et al. Anatomical subgroup analysis of the MERIDIAN cohort: failed commissuration. Ultrasound Obstet Gynecol. 2017;50:753-760.

27. Rüland AM, Berg C, Gembruch U, Geipel A. Prenatal Diagnosis of Anomalies of the Corpus Callosum over a 13-Year Period. Ultraschall Med. 2016;37:598-603.

28. Ozyüncü O, Yazıcıoğlu A, Turğal M. Antenatal diagnosis and outcome of agenesis of corpus callosum: A retrospective review of 33 cases. J Turk Ger Gynecol Assoc. 2014; 15:18-21.

29. Kasprian G, Brugger PC, Schöpf V, et al. Assessing prenatal white matter connectivity in commissural agenesis. Brain. 2013;136:168-79. 
30. Ghi T, Carletti A, Contro E, et al. Prenatal diagnosis and outcome of partial agenesis and hypoplasia of the corpus callosum. Ultrasound Obstet Gynecol. 2010;35:35-41.

31. Fratelli N, Papageorghiou AT, Prefumo F, Bakalis S, Homfray T, Thilaganathan B. Outcome of prenatally diagnosed agenesis of the corpus callosum. Prenat Diagn. 2007;27:512-7.

32. Rickard S, Morris J, Paley M, Griffiths P, Whitby E. In utero magnetic resonance of nonisolated ventriculomegaly: Does ventricular size or morphology reflect pathology? Clin Radiol. 2006;61:844-53.

33. Volpe P, Paladini D, Resta M, et al. Characteristics, associations and outcome of partial agenesis of the corpus callosum in the fetus. Ultrasound Obstet Gynecol. 2006;27:509-16.

34. Glenn OA, Goldstein RB, Li KC, et al. Fetal magnetic resonance imaging in the evaluation of fetuses referred for sonographically suspected abnormalities of the corpus callosum. $\mathrm{J}$ Ultrasound Med. 2005;24:791-804.

35. Ismail KM, Ashworth JR, Martin WL, et al. Fetal magnetic resonance imaging in prenatal diagnosis of central nervous system abnormalities: 3-year experience. J Matern Fetal Neonatal Med. 2002;12:185-90.

36. van Doorn M, Oude Rengerink K, Newsum EA, Reneman L, Majoie CB, Pajkrt E. Added value of fetal MRI in fetuses with suspected brain abnormalities on neurosonography: a systematic review and meta-analysis. J Matern Fetal Neonatal Med. 2016;29:2949-61.

37. Jarvis D, Mooney C, Cohen J, et al. A systematic review and meta-analysis to determine the contribution of mr imaging to the diagnosis of foetal brain abnormalities In Utero. Eur Radiol. 2017;27:2367-2380.

38. Malinger G, Paladini D, Pilu G, Timor-Tritsch IE. Fetal cerebral magnetic resonance imaging, neurosonography and the brave new world of fetal medicine. Ultrasound Obstet Gynecol. 2017;50:679-680.

39. Malinger G, Lerman-Sagie T, Watemberg N, Rotmensch S, Lev D, Glezerman M. A normal second-trimester ultrasound does not exclude intracranial structural pathology. Ultrasound Obstet Gynecol 2002; 20:51-56. 


\section{Legends tables and figure}

Table 1. General characteristics of the studies included in the systematic review.

Footnote: GA, gestational age; MRI, magnetic resonance imaging; US, ultrasound; ACC, agenesis of corpus callosum; cACC, complete agenesis of corpus callosum; pACC: partial agenesis of corpus callosum.

Table 2. Quality assessment of the included studies according to Newcastle-Ottawa Scale (NOS) for cohort studies; a study can be awarded a maximum of one star for each numbered item within the Selection and Outcome categories. A maximum of two stars can be given for Comparability.

Table 3. Pooled proportions for the rate of additional anomalies detected only at MRI and postnatal imaging in fetuses with isolated complete agenesis of corpus callosum .

Table 4. Pooled proportions for the rate of additional anomalies detected only at MRI and postnatal imaging in fetuses with isolated partial agenesis of corpus callosum.

Table 5. Pooled proportions for the rate of different additional anomalies detected only at MRI in fetuses with isolated complete and partial agenesis of corpus callosum.

Table 6. Pooled proportions for the rate of different additional anomalies missed also at MRI and detected only at post-natal imaging in fetuses with isolated complete and partial agenesis of corpus callosum.

Figure 1. Systematic review flowchart. USS, ultrasound; MRI, magnetic resonance imaging; ACC, agenesis of corpus callosum.

\section{Supporting Information legends}


Table S1. Excluded studies and reason for the exclusion.

Table S2. Search strategy.

This article is protected by copyright. All rights reserved 
Table 1. General characteristics of the studies included in the systematic review.

\begin{tabular}{|c|c|c|c|c|c|c|c|c|c|c|c|}
\hline Author & Year & Country & Study design & Study period & GA at MRI (w) & $\begin{array}{c}\text { Interval } \\
\text { between } \\
\text { US and } \\
\text { MRI (w) }\end{array}$ & $\begin{array}{l}\text { MRI field } \\
\text { strength } \\
\text { (T) }\end{array}$ & US assessment & Callosal anomaly & Fetuses & $\begin{array}{c}\text { Isolated } \\
\text { ACC }\end{array}$ \\
\hline Turkyilmaz ${ }^{22}$ & 2019 & Turkey & Retrospective & $2012-2017$ & $28.6(+/-4.1)$ & $4.1 \pm 3.3$ & 1.5 & Neurosonography & cACC, pACC & 36 & 20 \\
\hline Santirocco $^{23}$ & 2019 & Spain & Retrospective & $2007-2015$ & $28-34$ weeks & NS & 1.5 & Neurosonography & cACC, pACC & 86 & 37 \\
\hline Masmejan $^{24}$ & 2019 & Canada & Retrospective & $2008-2018$ & NS & NS & 1.5 & Neurosonography & cACC, pACC & 135 & 19 \\
\hline $\mathrm{deWit}^{25}$ & 2017 & The Netherlands & Retrospective & $2008-2015$ & $25(22-33)$ & NS & 1.5 & Neurosonography & cACC & 25 & 8 \\
\hline Griffiths $^{26}$ & 2017 & United Kingdom & Prospective & 2011-2014 & $>18$ weeks & $\begin{array}{c}\text { within } 14 \\
\text { days }\end{array}$ & 1.5 & NS & $\mathrm{aCC}$ & 79 & 55 \\
\hline Ruland $^{27}$ & 2015 & Germany & Retrospective & $1999-2012$ & NS & NS & NS & Neurosonography & cACC, pACC & 140 & 41 \\
\hline Özyüncï ${ }^{28}$ & 2014 & Turkey & Retrospective & $2002-2012$ & NS & NS & 1,5 & NS & cACC, pACC & 33 & 7 \\
\hline Kasprian $^{29}$ & 2013 & Austria & Prospective & NS & $27.6+/-6.1$ & NS & 1.5 & NS & cACC, pACC & 20 & 13 \\
\hline $\mathrm{Ghi}^{30}$ & 2010 & Italy & Retrospective & $1998-2008$ & NS & NS & 1.5 & Neurosonography & pACC & 19 & 4 \\
\hline Fratelli $^{31}$ & 2007 & United Kingdom & Retrospective & 1993-2003 & 26.8 & NS & 1.5 & NS & cACC & 129 & 35 \\
\hline Rickard $^{32}$ & 2006 & United Kingdom & Retrospective & $1999-2004$ & $26.5(20-35)$ & $\begin{array}{c}\text { Within } 4 \\
\text { days }\end{array}$ & 1.5 & NS & & 40 & 5 \\
\hline Volpe $^{33}$ & 2006 & Italy & Retrospective & 1996-2005 & $21-34$ & NS & NS & Neurosonography & $\mathrm{pACC}$ & 19 & 5 \\
\hline Glenn $^{34}$ & 2005 & USA & Retrospective & 1997-2002 & $\begin{array}{c}23.0(19.7- \\
32.4)\end{array}$ & $\begin{array}{c}1.5(0-17) \\
\text { days }\end{array}$ & 1.5 & NS & cACC, pACC & 10 & 1 \\
\hline Ismail $^{35}$ & 2002 & United Kingdom & Retrospective & 1998-2001 & $27.52(21-34)$ & $\begin{array}{c}\text { Within } 10 \\
\text { days }\end{array}$ & 1.5 & NS & cACC, pACC & 27 & 8 \\
\hline
\end{tabular}

This article is protected by copyright. All rights reserved 
Table 2. Quality assessment of the included studies according to Newcastle-Ottawa Scale (NOS) for cohort studies; a study can be awarded a maximum of one star for each numbered item within the Selection and Outcome categories. A maximum of two stars can be given for Comparability.

\begin{tabular}{|l|l|l|c|c|}
\hline Author & Year & Selection & Comparability & Outcome \\
\hline Turkyilmaz & 2019 & $\star \star \star$ & $\star$ & $\star \star$ \\
\hline Santirocco $^{23}$ & 2019 & $\star \star \star$ & $\star$ & $\star \star$ \\
\hline Masmejan $^{24}$ & 2019 & $\star \star \star$ & $\star$ & $\star \star$ \\
\hline deWit $^{25}$ & 2017 & $\star \star \star$ & $\star$ & $\star \star$ \\
\hline Griffiths $^{26}$ & 2017 & $\star \star \star$ & $\star \star$ & $\star \star$ \\
\hline Ruland $^{27}$ & 2015 & $\star \star \star$ & $\star$ & $\star \star$ \\
\hline Özyüncï $^{28}$ & 2014 & $\star \star \star$ & $\star$ & $\star \star$ \\
\hline Kasprian $^{29}$ & 2013 & $\star \star$ & $\star$ & $\star \star$ \\
\hline Ghi $^{30}$ & 2010 & $\star \star \star$ & $\star$ & $\star \star$ \\
\hline Fratelli $^{31}$ & 2007 & $\star \star \star$ & $\star$ & $\star \star$ \\
\hline Rickard $^{32}$ & 2006 & $\star \star \star$ & $\star$ & $\star \star$ \\
\hline Volpe $^{33}$ & 2006 & $\star \star \star$ & $\star$ & $\star \star$ \\
\hline Glenn $^{34}$ & 2005 & $\star \star$ & $\star$ & $\star \star$ \\
\hline Ismail $^{35}$ & 2002 & $\star \star \star$ & $\star$ & $\star \star$ \\
\hline
\end{tabular}

This article is protected by copyright. All rights reserved 
Table 3. Pooled proportions for the rate of additional anomalies detected only at MRI and post-natal imaging in fetuses with isolated complete ACC.

\begin{tabular}{|c|c|c|c|c|c|}
\hline Outcome & Studies & $\begin{array}{l}\text { Fetuses } \\
(\mathbf{n} / \mathbf{N})\end{array}$ & $\begin{array}{l}\text { Raw proportions } \\
(95 \% \mathrm{CI})\end{array}$ & $\mathbf{I}^{2}$ & $\begin{array}{l}\text { Pooled proportions } \\
(95 \% \mathrm{CI})\end{array}$ \\
\hline \multicolumn{6}{|c|}{ All fetuses with cACC } \\
\hline $\begin{array}{l}\text { Associated anomalies at } \\
\text { fetal MRI }\end{array}$ & 12 & $22 / 178$ & & 62.2 & $10.92(4.1-20.6)$ \\
\hline $\begin{array}{l}\text { Associated anomalies at } \\
\text { post-natal imaging }\end{array}$ & 9 & $4 / 108$ & & 3 & $4.31(1.4-8.8)$ \\
\hline \multicolumn{6}{|c|}{ Fetuses with cACC undergoing neurosonography } \\
\hline $\begin{array}{l}\text { Associated anomalies at } \\
\text { fetal MRI }\end{array}$ & 5 & $6 / 95$ & & 63.6 & $5.67(0.5-16.0)$ \\
\hline \multicolumn{6}{|c|}{ Fetuses with cACC undergoing standard US assessment" } \\
\hline $\begin{array}{l}\text { Associated anomalies at } \\
\text { fetal MRI }\end{array}$ & 7 & $16 / 83$ & & 30 & $18.47(7.8-32.4)$ \\
\hline
\end{tabular}

cACC, complete agenesis of corpus callosum; MRI, magnetic resonance imaging; US, ultrasound.

*: includes also studies not stating which type of ultrasound assessment was undertaken 
Table 4. Pooled proportions for the rate of additional anomalies detected only at MRI and post-natal imaging in fetuses with isolated partial ACC.

\begin{tabular}{|c|c|c|c|c|c|}
\hline Outcome & Studies & $\begin{array}{l}\text { Fetuses } \\
(\mathbf{n} / \mathbf{N})\end{array}$ & $\begin{array}{l}\text { Raw proportions } \\
(95 \% \mathrm{CI})\end{array}$ & $\mathbf{I}^{2}$ & $\begin{array}{l}\text { Pooled proportions } \\
(95 \% \mathrm{CI})\end{array}$ \\
\hline \multicolumn{6}{|c|}{ All fetuses with pACC } \\
\hline $\begin{array}{l}\text { Associated anomalies at } \\
\text { fetal MRI }\end{array}$ & 10 & $4 / 35$ & & 16.6 & $13.36(4.0-27.0)$ \\
\hline $\begin{array}{l}\text { Associated anomalies at } \\
\text { post-natal imaging }\end{array}$ & 8 & $4 / 28$ & & 22.9 & $16.16(5.9-30.3)$ \\
\hline \multicolumn{6}{|c|}{ Fetuses with pACC undergoing neurosonography } \\
\hline $\begin{array}{l}\text { Associated anomalies at } \\
\text { fetal MRI }\end{array}$ & 6 & $3 / 27$ & & 43.1 & $11.39(2.7-25.0)$ \\
\hline \multicolumn{6}{|c|}{ Fetuses pACC undergoing standard US assessment } \\
\hline $\begin{array}{l}\text { Associated anomalies at } \\
\text { fetal MRI }\end{array}$ & 4 & $1 / 8$ & & 0 & $16.91(1.3-44.8)$ \\
\hline
\end{tabular}

pACC, partial agenesis of corpus callosum; MRI, magnetic resonance imaging; US, ultrasound.

*: includes also studies not stating which type of ultrasound assessment was undertaken. 
Table 5. Pooled proportions for the rate of different additional anomalies detected only at MRI in fetuses with isolated complete and partial ACC.

\begin{tabular}{|c|c|c|c|c|c|}
\hline Outcome & Studies & $\begin{array}{l}\text { Fetuses } \\
(\mathbf{n} / \mathbf{N})\end{array}$ & $\begin{array}{l}\text { Raw proportions } \\
(95 \% \mathrm{CI})\end{array}$ & $\mathbf{I}^{2}$ & $\begin{array}{l}\text { Pooled proportions } \\
(95 \% \text { CI })\end{array}$ \\
\hline \multicolumn{6}{|c|}{ cACC } \\
\hline $\begin{array}{l}\text { Associated anomalies at } \\
\text { fetal MRI }\end{array}$ & 12 & $22 / 178$ & & 62.2 & $10.92(4.1-20.6)$ \\
\hline $\begin{array}{l}\text { Posterior fossa } \\
\text { anomalies }\end{array}$ & 12 & $3 / 178$ & & 0 & $2.84(0.9-5.7)$ \\
\hline Cortical anomalies & 12 & $11 / 178$ & & 8.4 & $6.28(3.0-10.6)$ \\
\hline Heterotopia & 12 & $4 / 178$ & & 0 & $3.51(1.3-6.6)$ \\
\hline Hemorrhage & 12 & $0 / 178$ & & 0 & $0(0-3.4)$ \\
\hline $\begin{array}{l}\text { Destructive brain } \\
\text { anomalies }\end{array}$ & 12 & $0 / 178$ & & 0 & $0(0-3.4)$ \\
\hline Complex anomalies & 12 & $4 / 178$ & & 24.6 & $3.25(0.8-7.3)$ \\
\hline \multicolumn{6}{|c|}{ pACC } \\
\hline $\begin{array}{l}\text { Associated anomalies at } \\
\text { fetal MRI }\end{array}$ & 10 & $4 / 35$ & & 16.6 & $13.36(4.0-27.0)$ \\
\hline $\begin{array}{l}\text { Posterior fossa } \\
\text { anomalies }\end{array}$ & 10 & $1 / 35$ & & 0 & $7.63(1.6-17.7)$ \\
\hline Cortical anomalies & 10 & $2 / 35$ & & 0 & $9.29(2.4-20.1)$ \\
\hline Heterotopia & 10 & $0 / 35$ & & 0 & $0(0-14.6)$ \\
\hline Hemorrhage & 10 & $0 / 35$ & & 0 & $0(0-14.6)$ \\
\hline $\begin{array}{l}\text { Destructive brain } \\
\text { anomalies }\end{array}$ & 10 & $0 / 35$ & & 0 & $0(0-14.6)$ \\
\hline Complex anomalies & 10 & $1 / 35$ & & 0 & $6.96(1.2-16.8)$ \\
\hline
\end{tabular}

This article is protected by copyright. All rights reserved 
Table 6. Pooled proportions for the rate of different additional anomalies missed also at MRI and detected only at post-natal imaging in fetuses with isolated complete and partial ACC.

\begin{tabular}{|c|c|c|c|c|c|}
\hline Outcome & Studies & $\begin{array}{l}\text { Fetuses } \\
(\mathbf{n} / \mathbf{N})\end{array}$ & $\begin{array}{l}\text { Raw proportions } \\
(95 \% \mathrm{CI})\end{array}$ & $\mathbf{I}^{2}$ & $\begin{array}{l}\text { Pooled proportions } \\
(95 \% \mathrm{CI})\end{array}$ \\
\hline \multicolumn{6}{|c|}{ cACC } \\
\hline $\begin{array}{l}\text { Associated anomalies at } \\
\text { post-natal MRI }\end{array}$ & 9 & $4 / 108$ & & 3 & $4.31(1.4-8.8)$ \\
\hline $\begin{array}{l}\text { Posterior fossa } \\
\text { anomalies }\end{array}$ & 9 & $0 / 108$ & & 0 & $0(0-4.9)$ \\
\hline Cortical anomalies & 9 & $2 / 108$ & & 0 & $3.11(0.7-7.1)$ \\
\hline Heterotopia & 9 & $0 / 108$ & & 0 & $0(0-4.9)$ \\
\hline Hemorrhage & 9 & $2 / 108$ & & 0 & $2.89(0.6-6.8)$ \\
\hline $\begin{array}{l}\text { Destructive brain } \\
\text { anomalies }\end{array}$ & 9 & $0 / 108$ & & 0 & $0(0-4.9)$ \\
\hline Complex anomalies & 9 & $0 / 108$ & & 0 & $0(0-4.9)$ \\
\hline \multicolumn{6}{|c|}{$\mathbf{p A C C}$} \\
\hline $\begin{array}{l}\text { Associated anomalies at } \\
\text { post-natal MRI }\end{array}$ & 8 & $4 / 28$ & & 22.9 & $16.16(5.9-30.3)$ \\
\hline $\begin{array}{l}\text { Posterior fossa } \\
\text { anomalies }\end{array}$ & 8 & $0 / 28$ & & 0 & $0(0-16.1)$ \\
\hline Cortical anomalies & 8 & $1 / 28$ & & 0 & $8.86(1.8-20.6)$ \\
\hline Heterotopia & 8 & $2 / 28$ & & 21.3 & $10.90(1.9-25.8)$ \\
\hline Hemorrhage & 8 & $0 / 28$ & & 0 & $0(0-16.1)$ \\
\hline $\begin{array}{l}\text { Destructive brain } \\
\text { anomalies }\end{array}$ & 8 & $1 / 28$ & & 0 & $7.89(1.3-19.2)$ \\
\hline Complex anomalies & 8 & $0 / 28$ & & 0 & $0(0-16.1)$ \\
\hline
\end{tabular}

cACC, complete agenesis of corpus callosum; pACC, partial agenesis of corpus callosum; MRI, magnetic resonance imaging. 


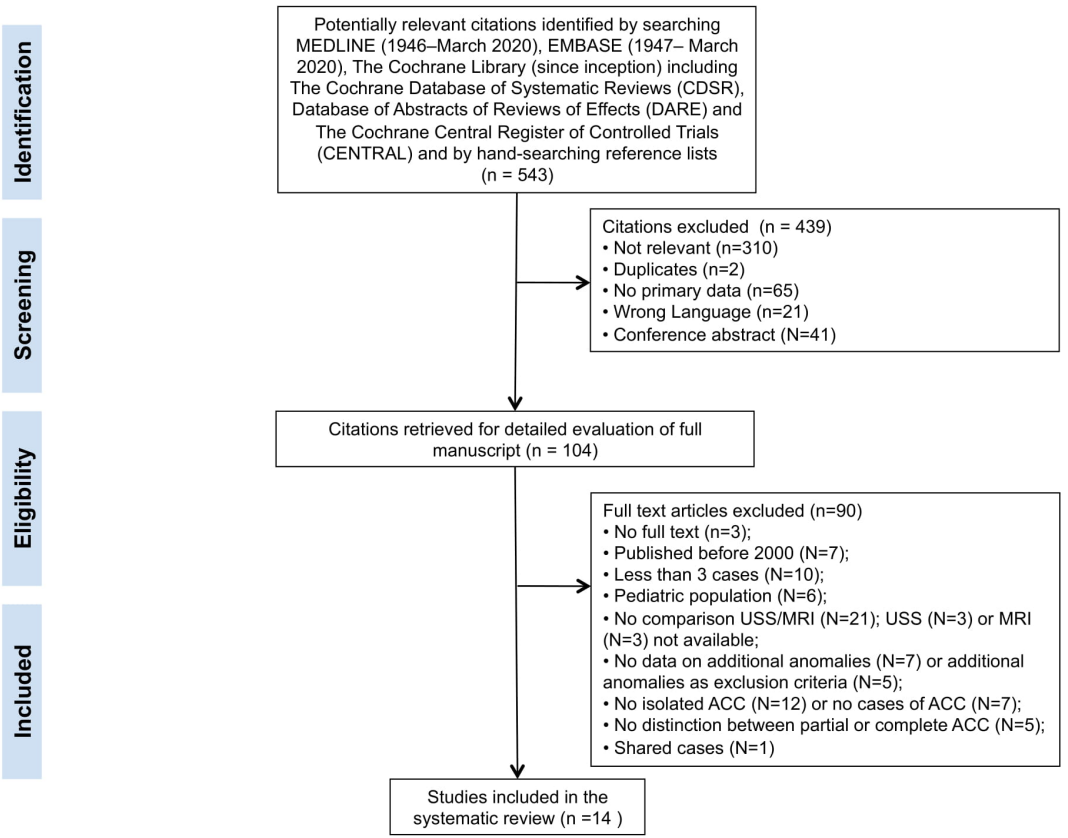

aogs_13958_f1.jpg 